\title{
Role of umbilical cord C-peptide levels in early prediction of hypoglycemia in infants of diabetic mothers
}

\author{
Ahlam M. Saber ${ }^{1}$, Magdy A. Mohamed², Abdelrahim A. Sadek ${ }^{1}$ and Ramadan A. Mahmoud ${ }^{\text {* }}$
}

\begin{abstract}
Background: Until now, diabetes during pregnancy has been associated with a high risk of maternal, fetal, and neonatal morbidities and mortalities. The main aim of this study was to evaluate the risk factors of hypoglycemia in infants of diabetic mothers (IDMs) and to study the relationship between umbilical cord (UC) C peptide levels and the risk of developing hypoglycemia.

Material and methods: UC blood C-peptide and serial serum blood glucose measurements were done for all included singleton newborns born to diabetic mothers during the study period. Maternal and neonatal data such as gestational age, maternal age, maternal weight, types of diabetics and its control, maternal glycated hemoglobin (HbA1C), birth weight, Apgar score, and neonatal complete blood picture were collected.

Results: In total, 83 IDMs met the inclusion criteria. Fifty-four (65.06\%) developed hypoglycemia and 29 (34.94\%) remained normoglycemic. However, there were no significant differences between hypoglycemic and normoglycemic IDMs in terms of types of maternal diabetics ( $P$ value $=0.41$ ), its duration ( $P$ value $=0.43$ ). The hypoglycemia peak occurred within the first $3 \mathrm{~h}$ of life, with $33.11 \pm 8.84 \mathrm{mg} / \mathrm{dl}$ for the hypoglycemia group and $54.10 \pm 6.66 \mathrm{mg} / \mathrm{dl}$ for the normoglycemic group ( $P$ value $<0.0001$ ). Most of the babies had no hypoglycemic manifestation (96.30\%). Neonates with hypoglycemia their mothers had poor diabetes control in the last trimester (HbA1C $7.09 \pm 0.96 \%)$ compared to normoglycemic babies (HbA1C $6.11 \pm 0.38 \%)$, ( $P$-value $<0.0001)$. The mean (SD) of UC C-peptide level in hypoglycemic neonates increased to $1.73 \pm 1.07 \mathrm{ng} / \mathrm{ml}$ compared to normoglycemic ones with $1.08 \pm 0.81 \mathrm{ng} / \mathrm{ml}(P$ value $=0.005)$.
\end{abstract}

Conclusion: Poor diabetes control, especially in the last trimester, is associated with neonatal hypoglycemia. Increased UC C-peptide levels could be used as an early indicator for the risk of developing neonatal hypoglycemia and a predictor for babies need neonatal admission.

Keywords: Infants of diabetic mothers, Umbilical cord C-peptide, Blood glucose, Full-term infant

\footnotetext{
* Correspondence: ramadan.aboelhassan@yahoo.com;

ramadan_aboelhassan@med.sohag.edu.eg

${ }^{1}$ Department of Pediatrics, Faculty of Medicine, Sohag University, 15

University Street, Sohag 82524, Egypt

Full list of author information is available at the end of the article
}

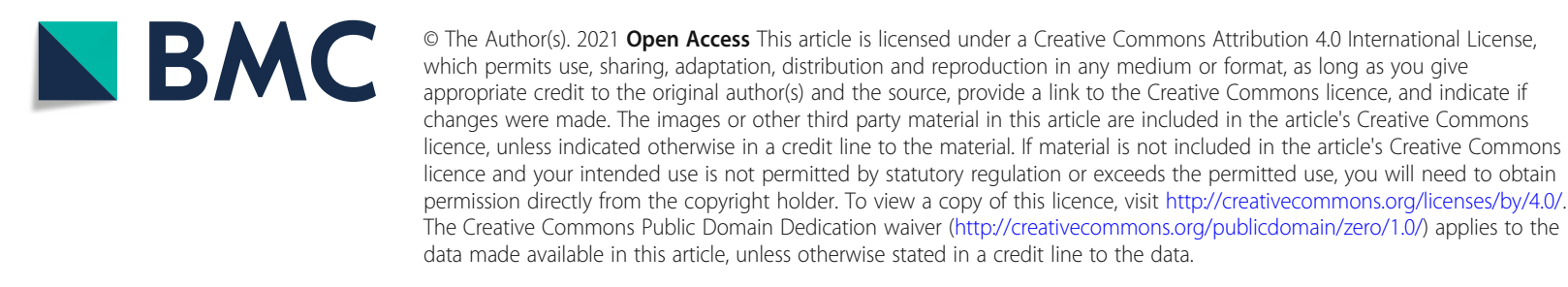




\section{Introduction}

Despite marked declines in neonatal mortality nowadays [1], diabetes mellitus (DM) with pregnancy either gestational (GDM), type 1 , or 2 is still associated with a risk of maternal, fetal, and neonatal morbidities and mortalities. Moreover, its prevalence did not decline, as GDM was about $8.74 \%$ on one cohort [2]. Infants of a diabetic mother (IDM) often have complications closely linked to fetal hyperglycemia and hyperinsulinemia, induced by maternal hyperglycemia [3].

In the first trimester, maternal hyperglycemia can cause spontaneous abortions or major birth defects such as truncus arteriosus or aortic coarctation. In the second and third trimesters, maternal hyperglycemia can cause fetal hyperglycemia and hyperinsulinemia, which lead to post-natal neonatal hypoglycemia, hypocalcemia, polycythemia, hyperbilirubinemia, septal myocardial hypertrophy, delayed lung maturation, and macrosomia [4].

Most IDMs develop asymptomatic hypoglycemia in the first postnatal hours, as after delivery, the transplacental supply of high glucose is stopped. Hyperinsulinemic hypoglycemia is a major risk factor for brain injury and subsequent neurodevelopmental impairments; therefore, rapid identification and prompt management of the newborn with hypoglycemia are essential to avoid brain damage [5]. In this context, early detection of babies at high risk of hypoglycemia is important.

Human C-peptide is a 31-amino acid chain secreted from the beta cells of the pancreas in equimolar ratio with the insulin level. It was chosen over insulin to estimate neonatal hyperinsulinemia, as $\mathrm{C}$-peptide has a long half-life and is unaffected by several blood processing conditions such as hemolysis $[6,7]$.

Maternal control during pregnancy mainly depends on diet and insulin control. The degree of control can be increased by serial measurements of blood glucose (BG) and glycated hemoglobin (HbA1C). However, HbA1C, now the current gold standard marker for glycemic control, reflects the BG level over the previous 2-3 months. It is a strong predictor of diabetic complications, and the cut-off used is $6.5 \%$ to diagnose diabetes [8].

Therefore, the main aim of this study is to evaluate the risk factors of hypoglycemia in IDM and its relation to maternal DM control in the last trimester. Furthermore, the relationship between $\mathrm{UC} C$ peptide and the risk of developing hypoglycemia was evaluated.

\section{Material and methods Design}

The current clinical study was performed at the neonatal intensive care unit (NICU) in the Pediatrics Department, in cooperation with the Department of Obstetrics and Gynecology, Egypt, during the period from June 2018 to
June 2019. Local ethical approval for the study was obtained from the Research Committee of the Faculty of Medicine at Sohag University (No. 321, 2018), and written informed consent was obtained from all parents of the children.

We included all singleton newborns born to diabetic mothers. Exclusion criteria included IDMs with preterm delivery, major congenital malformation at birth, severe perinatal asphyxia, twins, or erythroblastosis fetalis.

Eighty-three full-term singleton IDM newborns met the inclusion criteria and were enrolled in the study. The case group in this study consisted of any newborn infants delivered to DM mothers and who developed hypoglycemia within the first $24 \mathrm{~h}$ of life (BG less than $47 \mathrm{mg} / \mathrm{dl}$ ), other IDMs maintaining normoglycemic during the study period served as controls. Both the cases and the controls groups were drawn from the same population characteristics.

Maternal data such as maternal age, gestational age, maternal weight, type and duration of DM, maternal drugs for the control of DM, maternal diseases such as pre-eclampsia, premature rupture of membranes (PROM), mode of delivery, and the presence of meconium in the amniotic fluid were recorded. Maternal HbA1C was performed. Neonatal data such as gender, neonatal weight, Apgar score at $1 \mathrm{~min}$ and at $5 \mathrm{~min}$, causes of admission to NICU, if indicated, birth injuries, and detailed systemic examination were recorded. Observation for any hypoglycemia manifestations as (irritability, jitteriness, and convulsions) were done during NICU admission or in the nursery until babies discharged from hospital. Furthermore, BG measurements (Roche HITACHI Cobas C-311 Auto-Analyzer System) were performed at birth, after $30 \mathrm{~min}$, and after 1, 3, 6, 12, 18, and 24h; follow-up BG evaluations were performed until BG was normalized. We also determined complete blood count (Cell Dyn 3700, automated cell counter, Abbott Diagnostics, USA), electrolytes, CRP, and blood group. Neonatal outcome for neonates admitted to NICU were recorded. Echocardiography study were done before discharge for all IDM newborns met the inclusion criteria and were enrolled in the study.

Approximately $3 \mathrm{~mL}$ of UC blood were drawn immediately after delivery from all infants who met the inclusion criteria. The blood was chilled to $4{ }^{\circ} \mathrm{C}$, centrifuged as soon as possible, and stored at $-84^{\circ} \mathrm{C}$. UC serum Cpeptide was measured using a third-generation enzymelinked immunosorbent assay (ELISA) (Modular Analytics E170, Roche Diagnostics, Singapore).

\section{Data analysis}

Data were analyzed using STATA version 14.2 (Stata Statistical Software: Release 14.2 College Station, TX: 
Stata Corp LP.). Quantitative data were represented as mean, standard deviation, median, and range. Data were subjected to student $t$-test to compare means of two groups. When the data were not normally distributed, Mann-Whitney's test was applied. Qualitative data were presented as number and percentage and compared using either the Chi square test or Fisher's exact test. Graphs were generated using the software packages Excel or STAT; differences were considered significant at a $P$ value below 0.05 .

\section{Results}

\section{Patient characteristics}

In total, 83 IDM met the inclusion criteria and were included in this study. Of these, 54 (65.06\%), developed hypoglycemia and 29 (34.94\%) remained normoglycemic. However, there were no significant different maternal or neonatal differences between hypoglycemic and normoglycemic IDMs, even for types of maternal diabetics $(P$ value $=0.41)$, its duration ( $P$ value $=0.43)$, or measurements used for control of diabetes $(P$ value $=0.62)$, as shown in Tables 1 and 2. Furthermore, IDM with hypoglycemia had higher birth weights $(3.90 \pm 0.81) \mathrm{kg}$ when compared to IDM with normoglycemia $(3.78 \pm$ $0.49) \mathrm{kg}$, although this difference was not statistically significant $(P$-value $=0.07)$. As regard the echocardiographic finding, ventricular septal hypertrophy $(\geq 6 \mathrm{~mm}$ ) were found in 21 (38.89\%) IDM with hypoglycemia compared to $10(34.48 \%)$ IDM with normoglycemia $(P$-value $=0.3)$.

\section{Blood glucose measurements}

In the hypoglycemic group, the peak of hypoglycemia occurred at the first $3 \mathrm{~h}$ of life, with $33.11 \pm 8.84 \mathrm{mg} / \mathrm{dl}$ for the hypoglycemia group and $54.10 \pm \mathrm{mg} / \mathrm{dl}$ for the normoglycemic group $(P=0.0001$; Fig. 1$)$. Furthermore, of a total 54 patients developing hypoglycemia, most of the babies had no hypoglycemic manifestation (96.30\%), and only two patients had manifestation one, with lethargy and poor suckling (3.70\%).

\section{Glycated hemoglobin ( $\mathrm{HbA1C}$ ) measurements}

As shown in Fig. 2, there were a statistically significant difference between patients developing hypoglycemia and having mothers had poor diabetes control in the last trimester $(\mathrm{HbA} 1 \mathrm{C} \quad 7.09 \pm 0.96 \%)$ compared to
Table 1 Comparison between normoglycemic and hypoglycemic infant according to maternal characteristics

\begin{tabular}{|c|c|c|c|}
\hline Variable & $\begin{array}{l}\text { Normoglycemic } \\
N=29\end{array}$ & $\begin{array}{l}\text { Hypoglycemic } \\
N=54\end{array}$ & $P$ value \\
\hline \multicolumn{4}{|l|}{ Maternal age (years) } \\
\hline Mean \pm SD & $36.03 \pm 6.93$ & $35.22 \pm 4.35$ & 0.51 \\
\hline \multicolumn{4}{|c|}{ Maternal weight (kg) } \\
\hline Mean \pm SD & $77.76 \pm 8.60$ & $79.54 \pm 7.90$ & 0.35 \\
\hline \multicolumn{4}{|l|}{ Preeclampsia } \\
\hline Yes & $9(31.03 \%)$ & $21(38.89 \%)$ & 0.18 \\
\hline \multicolumn{4}{|l|}{$\mathrm{PROM}>18 \mathrm{~h}$} \\
\hline Yes & $2(6.89)$ & $4(7.41 \%)$ & 0.69 \\
\hline \multicolumn{4}{|l|}{ Mode of delivery } \\
\hline CS & $24(82.75 \%)$ & $44(81.48 \%)$ & 0.25 \\
\hline NVD & $5(17.24 \%)$ & $10(18.51 \%)$ & \\
\hline \multicolumn{4}{|l|}{ Type of DM } \\
\hline Gestational DM & $12(41.38 \%)$ & $23(42.59 \%)$ & 0.41 \\
\hline Type 1 & 0 & $3(5.56 \%)$ & \\
\hline Type 2 & $17(58.62 \%)$ & $28(51.85 \%)$ & \\
\hline \multicolumn{4}{|c|}{ Duration of DM (years) } \\
\hline Mean $\pm S D$ & $2.21 \pm 2.18$ & $3.18 \pm 4.3$ & 0.43 \\
\hline \multicolumn{4}{|c|}{ Type of treatment of DM } \\
\hline Diet & $1(3.45 \%)$ & $5(9.26 \%)$ & 0.62 \\
\hline Insulin & $23(79.31 \%)$ & $40(74.07 \%)$ & \\
\hline Oral\nsulin & $5(17.24 \%)$ & $9(16.67 \%)$ & \\
\hline
\end{tabular}

Table 2 Comparison between normoglycemic and hypoglycemic infant according to Neonatal characteristics

\begin{tabular}{|c|c|c|c|}
\hline Variable & $\begin{array}{l}\text { Normoglycemic } \\
N=29\end{array}$ & $\begin{array}{l}\text { Hypoglycemic } \\
N=54\end{array}$ & $P$ value \\
\hline \multicolumn{4}{|c|}{ Gestational age (weeks) } \\
\hline Mean \pm SD & $38.28 \pm 2.59$ & $38.98 \pm 2.01$ & 0.11 \\
\hline \multicolumn{4}{|l|}{ Gender } \\
\hline Female & $20(68.97 \%)$ & $30(55.56 \%)$ & 0.23 \\
\hline Male & $9(31.03 \%)$ & $24(44.44 \%)$ & \\
\hline \multicolumn{4}{|c|}{ Neonatal weight (kg) } \\
\hline Mean \pm SD & $3.78 \pm 0.49$ & $3.90 \pm 0.81$ & 0.07 \\
\hline \multicolumn{4}{|l|}{ APGAR score 1 Min } \\
\hline Median (range) & $8(7-9)$ & $8(6-9)$ & 0.44 \\
\hline \multicolumn{4}{|l|}{ APGAR score 5 Min } \\
\hline Median (range) & $10(7-10)$ & $10(8-10)$ & 0.45 \\
\hline \multicolumn{4}{|l|}{ Hct (\%) } \\
\hline Mean \pm SD & $53.22 \pm 3.59$ & $51.59 \pm 4.20$ & 0.08 \\
\hline \multicolumn{4}{|l|}{ WBCs (thousands) } \\
\hline Mean \pm SD & $11.07 \pm 1.81$ & $12.06 \pm 3.47$ & 0.16 \\
\hline \multicolumn{4}{|l|}{ Platelets (thousands) } \\
\hline Mean \pm SD & $221.69 \pm 37.10$ & $213.91 \pm 45.37$ & 0.43 \\
\hline \multicolumn{4}{|c|}{ Serum total Ca $(\mathrm{mg} / \mathrm{dl})$} \\
\hline Mean \pm SD & $8.5 \pm 0.71$ & $8.32 \pm 0.39$ & 0.13 \\
\hline \multicolumn{4}{|c|}{ Ventricular septal hypertrophy ( $\geq 6 \mathrm{~mm}$ ) } \\
\hline Number (\%) & $10(34.48 \%)$ & 21 (38.89\%) & 0.3 \\
\hline
\end{tabular}




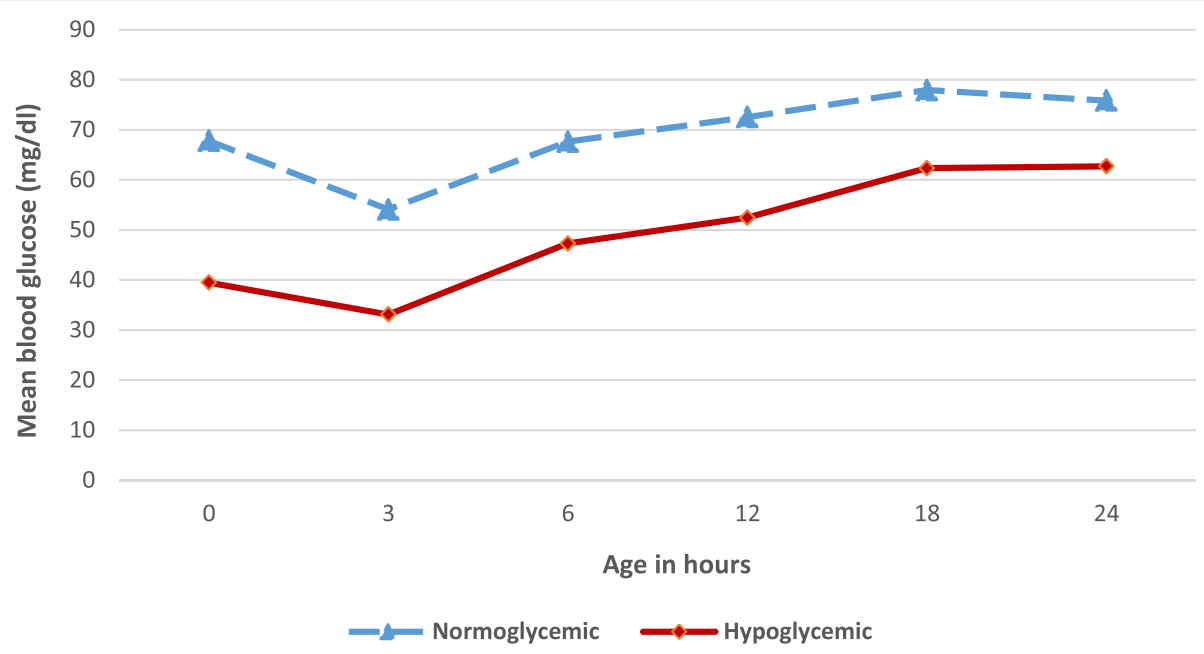

Fig. 1 Comparison between normoglycemic and hypoglycemic IDM according to blood glucose during the first $24 \mathrm{~h}$ of life

normoglycemic babies of mothers with good diabetes control (HbA1C $6.11 \pm 0.38 \%)$, ( $P$-value $<0.0001)$.

\section{C-peptide measurements}

Moreover, as shown in Fig. 3, the mean (SD) of UC Cpeptide in the case group was $1.73 \pm 1.07 \mathrm{ng} / \mathrm{ml}$, ranging from 0.13 to $3.3 \mathrm{ng} / \mathrm{ml}$, while in the control group, it was $1.08 \pm 0.81 \mathrm{ng} / \mathrm{ml}$, ranging from 0.25 to $3.9 \mathrm{ng} / \mathrm{ml}$; there was a statistically significant difference between the two studied groups $(P$ value $=0.005)$.

\section{Discussion}

Our results show that poor diabetes control, especially in the last trimester, is associated with neonatal hypoglycemia. Furthermore, increased UC C-peptide levels could be used as an early indicator for risk of developing neonatal hypoglycemia and a predictor for babies need neonatal admission.

Major risk factors for developing GDM during pregnancy include increased maternal age, a family history of diabetes, a history of GDM in a previous pregnancy, a history of macrosomia in a previous pregnancy, and an

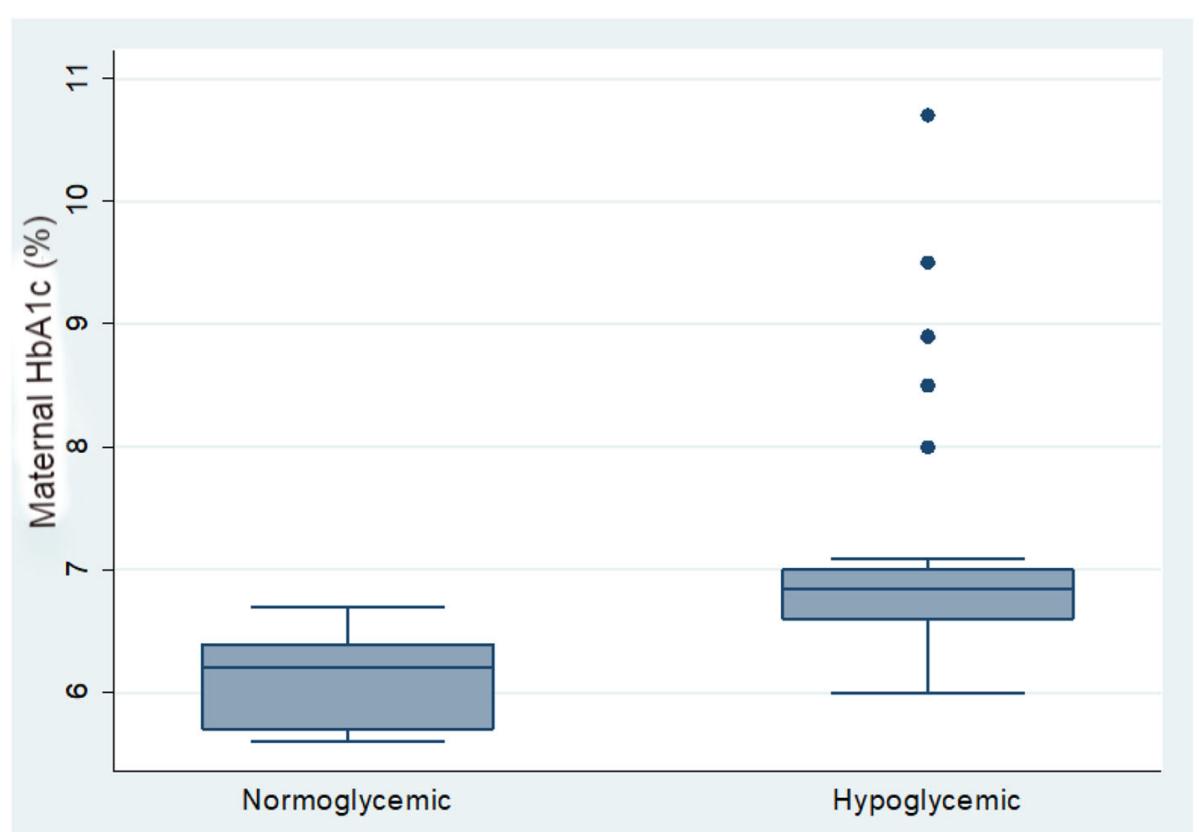

Fig. 2 Comparison between normoglycemic and hypoglycemic infant according to maternal HbA1c 


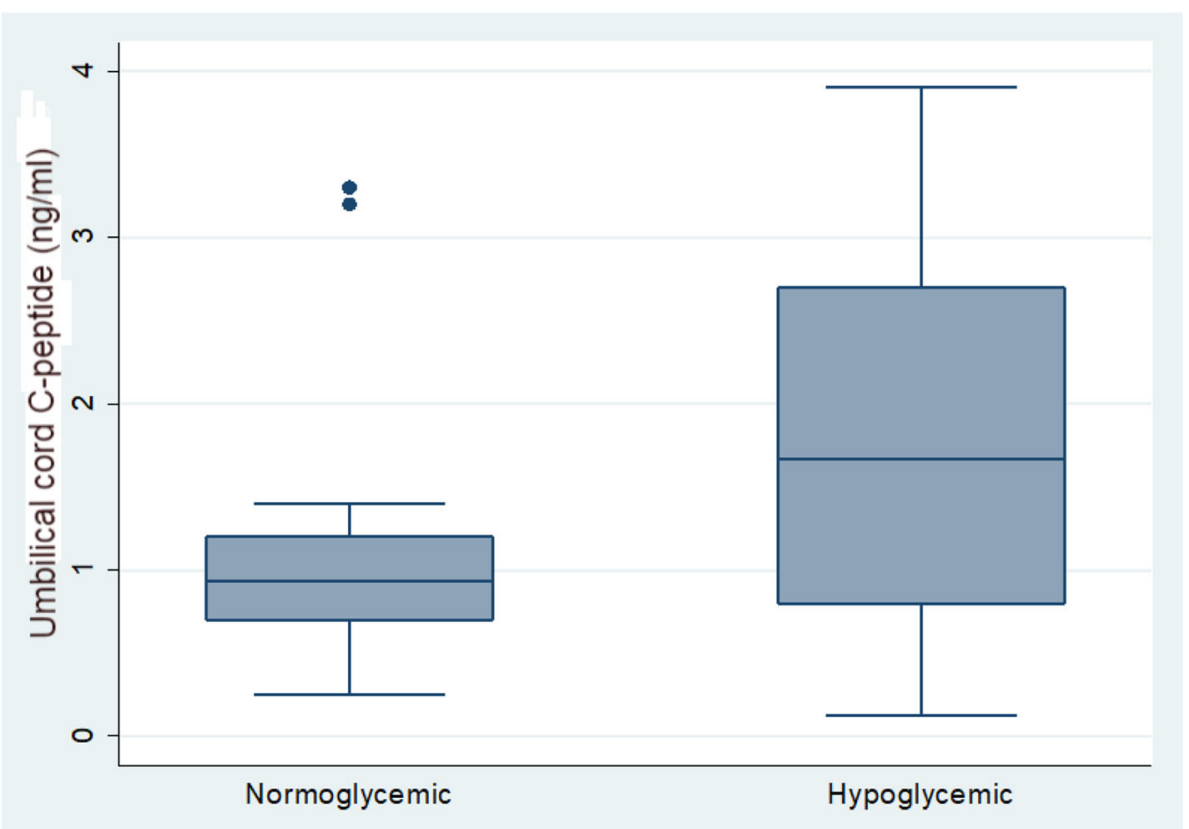

Fig. 3 Comparison between normoglycemic and hypoglycemic IDM according serum level of umbilical cord C-peptide

increased pre-gravid body mass index [2]. In our study, 35 (42.17\%) mothers had GDM, the mean \pm SD of maternal age was $36.03 \pm 6.93$ years, and the mean $\pm \mathrm{SD}$ of maternal weight was $77.76 \pm 8.60 \mathrm{~kg}$.

In this study, at least one attack of hypoglycemia within the first $3 \mathrm{~h}$ of life developed in IDM in about $65.06 \%$ neonates. This is comparable to the findings of a study by Begum et al. [9], in which the occurrence of hypoglycemia was $73.3 \%$ within the first $6 \mathrm{~h}$ of life, while in Agrawal et al. [10], only $47 \%$ of the infants developed hypoglycemia during the first $2 \mathrm{~h}$ of life. In our study, of a total of 54 patients developing hypoglycemia, most cases were asymptomatic hypoglycemia (96.30\%), which is in agreement with the findings of previous studies. For example, in a study by Begum et al. [9], about $93.3 \%$ of the hypoglycemic babies were asymptomatic, while in Agrawal et al. [10] and Van Howe et al. [11], 100\% of the hypoglycemic babies were asymptotic.

Hypoglycemia is the most common metabolic disorder reported in full-term and preterm infants. The definition of hypoglycemia as well as its clinical significance and optimal time at management remain controversial [12]. Previously, asymptomatic hypoglycemia has been considered to be of no clinical significance [13]. However, numerous studies have demonstrated that even asymptomatic hypoglycemia can have a poor neurodevelopmental outcome immediately after birth [14] and even later on up to school age [15]. Therefore, early detection and management of even asymptomatic hypoglycemia are critically important.

In our study, the demographic characteristics of the mothers were similar in hypoglycemic and normoglycemic groups, such as maternal age, maternal weight, and type and duration of diabetes, with similar results when compared to Begum et al. [9]. In contrast, Agarwal et al. [10] who found that IDMs with hypoglycemia had significantly longer durations of maternal diabetes. In our study, infants with hypoglycemia had higher birth weights than normoglycemic babies, although this difference was not statistically significant. This is in agreement with Dawid et al. [16], who found neither a correlation between birth weight and maternal fructosamine level nor between birth weight and maternal HBA1C level. In contrast, Metzger et al. [17] and Cooper et al. [18] found that infants with a higher birth weight were more likely to develop hypoglycemia and hyperinsulinemia than the control group with a normal birth weight, suggesting physiologic relationships between maternal hyperglycemia and fetal insulin production.

We observed a statistically significant difference between infants developing hypoglycemia and having mothers with poor diabetes control in the last trimester and normoglycemic babies. This finding is in agreement with Griffiths et al. [19] and Fallucca et al. [20], who observed a correlation between infant hypoglycemia and poor maternal diabetes control. Poor diabetes control in our cases group mainly related to poor patients 
compliance and/or resistance against treatment due to lack of regular ant-natal visits as most cases came to our tertiary hospital referred from primary hospitals just before delivery. In contrast, other researchers found that even in well-controlled diabetic mothers, the incidence of early hypoglycemia in infants is still high, particularly in those mothers who had a longer duration of diabetes $[10,16,21]$. Even for some other IDM complications, we found no correlation between the presence of ventricular septal hypertrophy in IDM either with hypoglycemia or normglycemia cases. Other research by Vela-Huerta et al. [22], found no correlation between the increased prevalence of asymmetric septal hypertrophy and the state of maternal diabetic control.

Furthermore, in this study, we found a statistically significant increase in UC C-peptide levels in infants who developed hypoglycemia when compared to the control group ( $P$ value $=0.005)$, suggesting that $C$-peptide can be used as an early predicator for hypoglycemia in IDMs. This finding is comparable with other studies reporting that cord C-peptide levels were inversely related to BG concentrations in the early postnatal period $[9,17,18$, 20]. Furthermore, the increased UC C-peptide level may be associated with infant macrosomia $[17,23]$ and neonatal septal hypertrophic cardiomyopathy [18]. Therefore hyperinsulemia is the cornstone in the development of many complication in IDM [24]. However, some patients in our case group showing hypoglycemic without elevation of $\mathrm{C}$-Peptide, this points needed to be discussed in further research to study the relation of CPeptide measurements and hypoglycemia severity.

In conclusion, poor diabetes control, especially in the last trimester, is associated with neonatal hypoglycemia. Furthermore, increased UC C-peptide levels could be used as an early indicator for risk of developing neonatal hypoglycemia and a predictor for babies need neonatal admission. However, further studies with larger sample sizes are needed to determine the cost effectiveness of this relatively costly test before it can be used routinely in daily care practice.

\section{Abbreviations}

BG: Blood glycose; DM: Diabetes mellitus; GMD: Gestational diabetes mellitus: HbA1C: Glycated hemoglobin; IDM: Infants of diabetic mothers; NICU: Neonatal intensive care unit; PROM: Premature rupture of membranes; UC: Umbilical cord

\section{Acknowledgements}

The authors thank http://proof-reading-services.com for language editing.

\section{Authors' contributions}

AMS, RAM are responsible for the study design, collection and interpretation of the data, manuscript writing. MAM study design, maternal data collection, participated drafting the manuscript. RAM, MAM performed statistical analysis, AAS responsible for study design, revised the manuscript. All authors reviewed and approved the final manuscript for publication.

\section{Funding}

The authors received no funding to perform this study.

\section{Availability of data and materials}

The datasets used and/or analyzed during the current study are available from the corresponding author on reasonable request.

\section{Ethics approval and consent to participate}

The research related to human subject use complied with all the relevant national regulations and institutional policies. Local ethical approval for the study was obtained from the Research Committee of the Faculty of Medicine at Sohag University, Egypt (No. 321, 2018). Written informed consent was obtained from all parents of the children.

\section{Consent for publication}

The authors declare that they have obtained the consent for publication from each parent's patient.

\section{Competing interests}

The authors declare that they have no competing interests.

\section{Author details}

${ }^{1}$ Department of Pediatrics, Faculty of Medicine, Sohag University, 15 University Street, Sohag 82524, Egypt. ${ }^{2}$ Department of Obstetrics and Gynecology, Faculty of Medicine, Sohag University, Sohag, Egypt.

Received: 12 November 2020 Accepted: 5 January 2021

Published online: 17 February 2021

\section{References}

1. Mathews TJ, Driscoll AK. Trends in infant mortality in the United States, 2005-2014. NCHS data brief. 2017;279:1-8

2. Di Cianni G, Volpe L, Lencioni C, Miccoli R, Cuccuru I, Ghio A, et al. Prevalence and risk factors for gestational diabetes assessed by universal screening. Diabetes Res Clin Pract. 2003:62(2):131-7.

3. Cordero L, Landon MB. Infant of the diabetic mother. Clin Perinatol. 1993; 20(3):635-48.

4. Cheng Y, Caughey A. Gestational diabetes: diagnosis and management. J Perinatol. 2008;28(10):657.

5. Kapoor RR, Flanagan SE, James C, Shield J, Ellard S, Hussain K. Hyperinsulinaemic hypoglycaemia. Arch Dis Child. 2009;94(6):450-7.

6. O'Rahilly S, Burnett MA, Smith RF, Darley JH, Turner RC. Haemolysis affects insulin but not C-peptide immunoassay. Diabetologia. 1987;30(6):394-6.

7. Wu ZQ, Lu J, Xu HG. Hemolysis affects C-peptide immunoassay. J Clin Lab Anal. 2016;30(6):1232-5.

8. Majeed NA. Glycated haemoglobin is a good predictor of neonatal hypoglycaemia in pregnancies complicated by diabetes. Malays J Pathol. 2011:33(1):21.

9. Begum MNN, Hassan MQ, Azad K. Relationship between umbilical cord Cpeptide and risk of hypoglycemia in infants of diabetic mothers. Bangladesh J Child Health. 2012;36(2):71-5.

10. Agrawal R, Lui K, Gupta J. Neonatal hypoglycaemia in infants of diabetic mothers. J Paediatr Child Health. 2000:36(4):354-6.

11. Van Howe RS, Storms MR. Hypoglycemia in infants of diabetic mothers: experience in a rural hospital. Am J Perinat. 2006;23(2):105-10.

12. Kallem VR, Pandita A, Gupta G. Hypoglycemia: when to treat? Clinical Medicine Insights: Pediatrics. 2017:11:1179556517748913.

13. Koivisto M, Blanco SM, Krause U. Neonatal symptomatic and asymptomatic hypoglycaemia: a follow-up study of 151 children. Dev Med Child Neurol. 1972;14(5):603-14.

14. Koh TH, Aynsley-Green A, Tarbit M, Eyre JA. Neural dysfunction during hypoglycaemia. Arch Dis Child. 1988;63(11):1353-8.

15. Stenninger E, Flink R, Eriksson B, Sahlen C. Long-term neurological dysfunction and neonatal hypoglycaemia after diabetic pregnancy. Arch dis Child-Fetal. 1998;79(3):F174-9.

16. Dawid G, Horodnicka JA, Petriczko E, Biczysko MA. Diabetes in pregnancy: cord blond insulin level and neonatal outcome in relation to maternal glycated haemoglobin A1c in last trimester of pregnancy. Pediatr Endocr Diabetes Met. 2009;15(4):253-9. 
17. Metzger BE, Persson B, Lowe LP, Dyer AR, Cruickshank JK, Deerochanawong $C$, et al. Hyperglycemia and adverse pregnancy outcome study: neonatal glycemia. Pediatrics. 2010;126(6):e1545-52.

18. Cooper MJ, Enderlein MA, Tarnoff H, Roge CL. Asymmetric septal hypertrophy in infants of diabetic mothers. Fetal echocardiography and the impact of maternal diabetic control. Am J Dis Child. 1992;146(2):226-9.

19. Griffiths RJ, Vinall PS, Stickland MH, Wales JK. Haemoglobin A1c levels in normal and diabetic pregnancies. Eur J Obstet Gynaecol Reprod Biol. 1987; 24(3):195-200.

20. Fallucca F, Maldonato A, lavicoli M, Di Rollo G, Di Biase N, Napoli A, et al. Influence of maternal metabolic control and insulin antibodies on neonatal complications and B cell function in infants of diabetic mothers. Diabetes Res Clin Pract. 1989;7(4):277-84.

21. Voormolen DN, DeVries JH, Sanson RME, Heringa MP, de Valk HW, Kok M, et al. Continuous glucose monitoring during diabetic pregnancy (GlucoMOMS): a multicentre randomized controlled trial. Diabetes Obes Metab. 2018;20(8):1894-902.

22. Vela-Huerta MM, Amador LN, Villagomez HVO, Ruiz AH, Guizar-Mendoza JM. Asymmetric Septal hypertrophy in appropriate for gestational age infants born to diabetic mothers. Indian Pediatr. 2019:56(4):314-6.

23. Annabestani Z, Heshmat R, Alyasin A, Larijani B. Amniotic fluid, maternal, and neonatal serum C-peptide as predictors of macrosomia: a pilot study. Iran J Diabetes Lipid Dis. 2009;15(8):129-36.

24. Kallem VR, Pandita A, Pillai A. Infant of diabetic mother: what one needs to know? J Matern Fetal Neonatal Med. 2020;33(3):482-92.

\section{Publisher's Note}

Springer Nature remains neutral with regard to jurisdictional claims in published maps and institutional affiliations.

Ready to submit your research? Choose BMC and benefit from:

- fast, convenient online submission

- thorough peer review by experienced researchers in your field

- rapid publication on acceptance

- support for research data, including large and complex data types

- gold Open Access which fosters wider collaboration and increased citations

- maximum visibility for your research: over $100 \mathrm{M}$ website views per year

At BMC, research is always in progress.

Learn more biomedcentral.com/submissions 